\title{
Changing the Service Model: Utilizing Tutor Center Models for Reference Desk Redesign
}

\author{
Jessica L. Bennett \\ Missouri State University \\ Tracy L. Stout \\ Missouri State University
}

Follow this and additional works at: https://bearworks.missouristate.edu/articles-lib

\section{Recommended Citation}

Bennett, Jessica L., and Tracy L. Stout. "Changing the Service Model: Utilizing Tutor Center Models for Reference Desk Redesign." Public Services Quarterly 17, no. 4 (2021): 248-255.

This article or document was made available through BearWorks, the institutional repository of Missouri State University. The work contained in it may be protected by copyright and require permission of the copyright holder for reuse or redistribution.

For more information, please contact BearWorks@library.missouristate.edu. 
CHANGING THE REFERENCE SERVICE MODEL

Introduction

In 2015, the Research and Instructional Services (RIS) Unit of Meyer Library at Missouri State University was challenged to update and rethink our service model and space. We had just recently changed our name from Reference and Government Information to Research and Instructional Services and had been operating in a traditional reference model, with a walk-up reference desk staffed primarily by faculty librarians. To provide cohesive direction for the unit, we first updated our mission and vision statement, as follows:

Mission: It is our responsibility to meet the instructional and research needs of the University community within the context of a quickly shifting informational environment. Our space, services, and collections should provide an interactive environment for teaching, learning, research, scholarship, and creative activities. In doing so, we will facilitate life-long learning, while continually making adjustments to better serve our constituents.

Vision: We will provide an environment that is welcoming, safe, and stimulating to meet the needs of the University community. We seek to acquire and maintain the necessary resources, in all formats, that will lead to a diverse and strong research collection, as well as the technological tools that will provide for seamless access. We will strive to foster the "customer comes first" service model in all interactions with our library patrons, even as we embrace the innovative, dynamic changes happening in our learning environment, while enthusiastically supporting the public affairs mission of the University.

Many colleges and universities are rethinking how they provide reference services. RIS wanted to provide the best possible research assistance to our campus community, while making the most of our space, and our personnel. This paper outlines our process for researching, designing, 
CHANGING THE REFERENCE SERVICE MODEL

and implementing our new space and service model, and the subsequent change in library organization, resulting in a combined desk.

\section{Literature review}

\section{Traditional reference}

"For many libraries, the physical reference desk is one of the most visible public service points (Alexander \& Wakimoto, 2019, p. 21)." This is largely the main reason that so much discussion has occurred about having a reference desk or not, how to staff the reference desk, and what the reference desk should look like. It seems that librarians have been discussing these aspects of the reference desk since 1975 (Alexander \& Wakimoto, 2019).

McClure and Bravender (2013) report that reference transactions (as reported to ARL), have not only decreased over the last ten years but have decreased by nearly 50 percent. Alexander and Wakimoto (2019) also discussed the decline in reference transactions along with several other factors including mission creep that has impacted academic libraries. This has led many academic libraries to take a hard look at their traditional reference model and the traditional reference desk. McClure and Bravender (2013) also point out that these statistics and other concerns have led to decisions about how to best staff reference desks with some librarians choosing to better allocate their time to provide instruction, research consultations, and other duties to better reach students. Having well trained front-line staff and students answer basic questions and transfer only those higher-level reference questions to librarians has been beneficial at many academic libraries. A study by Gratz and Gilbert (2011), concluded that the majority of students sought out a reference desk to ask for assistance while less than 25 percent 
CHANGING THE REFERENCE SERVICE MODEL

of students surveyed said they sought assistance from the general help desk. With their findings, Gratz and Gilbert decided to continue utilizing their traditional reference desk.

According to McClure and Bravender (2013), changes have been made to the traditional reference desk by other academic libraries to try and better meet the needs of their patrons and combat the decline in reference transactions. These changes have included building a single service point, trying different reference service models, and/or expanding online services.

\section{Reference service models}

Implementing an Inclusive Staffing Model for Today’s Reference Service (Nims, Storm, \& Stevens, 2014), informed us of additional ways to modify our service model. The three models discussed include the Brandeis model, hybrid model, and the inclusive model. The Brandeis model is two-tiered; first tier consists of trained staff/students who answer directional and basic queries, and then refer to a librarian when needed; second tier is librarian on-call (can be immediate or by appointment). The hybrid model is a reference desk model changed to information commons model; face-to-face reference, consultations, virtual reference, telephone and tech help from one desk, staffed by librarians and trained staff (in some instances librarians are again on-call for more in-depth reference questions). Finally, the inclusive staffing model shares elements of Brandeis and hybrid models and is tiered, utilizing well-trained staff and students. We liked elements of all three models, and our current desk schedule reflects this.

\section{Drop-in tutoring models}

O’Kelly et al. (2015), recognized that academic libraries are places where students can go to learn outside of the classroom. They touted the benefits of providing an area that felt safe for 
CHANGING THE REFERENCE SERVICE MODEL

students to not just ask questions, but to go through an entire process of learning that includes

"exploring, practicing, questioning their own understanding of issues and topics with a well-

training peer (p. 163)." They encouraged the idea that library students could be more than just a

bridge between the student asking a question and a librarian but could serve as a reference consultant versus a reference assistant. O'Kelly et al. (2015) went in-depth on what tutoring includes and the benefits to both the one receiving the tutoring and also the one providing the tutoring. Both parties are able to have a one-on-one conversation where they can "see body language and share knowledge (p.164)." Tutors also receive more training, learn more from these unique personal interactions, and gain additional skill sets compared to other students who provide basic assistance and referral services (O'Kelly et al., 2015). At the current time, libraries generally are not set up to provide research tutoring services in the same way that other areas such as Writing Centers or Math tutoring centers are on campus. With the popularity of these tutoring services on college campuses and with library literature encouraging the use of student assistants at the reference desk, it may behoove libraries to explore the tutoring aspect within reference service models.

Case study

While the Research and Instructional Services unit was challenged by library administration to make changes, we as a unit were aware of the changing nature of the reference interaction. Directional questions and assistance with printing were taking up more and more of our time on the desk. It was difficult to answer the true reference questions, while dealing with a jammed printer, and lacking an ideal place to demonstrate and discuss what was best for a given research query. Also, due to the nature of faculty duties, the library faculty were having difficulty attending meetings, teaching instruction sessions, providing research consultations, 
CHANGING THE REFERENCE SERVICE MODEL

maintaining their own research, etc, while keeping a full load of reference desk hours. Our information literacy instruction sessions have taken a larger role in our efforts as a unit, and we have worked to increase the number of sessions each RIS faculty librarian teaches in a semester. These sessions are a wonderful way to provide instruction and guidance to a larger number of students at once, but the amount of prep time is not insubstantial. At this time there was also discussion of the reference and circulation desk merging, the main argument being efficiency. RIS knew we would not be able to provide the kind of service we wanted if in a combined desk scenario. This challenge provided us a perfect opportunity to redesign both our physical desk and the way we provide service, keeping our mission and vision front and center.

While many of the obstacles we encountered during the remodel are not unique to Meyer Library (limited resources, training, buy-in, etc.), hence the focus on tutoring centers, we wanted to look beyond library solutions. The Missouri State University BearClaw tutoring and writing center is a resource on campus for students seeking tutoring in various subjects or assistance with writing projects. One of the most utilized services at the BearClaw is their drop-in math tutoring table. The table is staffed by current students, who have been trained to provide tutoring. No appointments are necessary, students can drop by during their open hours for help with homework or preparing for tests. The set-up is simple; working height tables form a semicircle, with students sitting around the outside, and tutors on the interior with tall whiteboards for demonstrating. RIS really loved two parts of this, the peer to peer aspect, and the approachability of the tables. Many studies have found the value of the peer to peer model, and our own observations confirmed this. When approaching the desk, if they have a choice between a faculty librarian, or a student worker, the students almost unerringly prefer to first approach the student worker. The second aspect, the approachability of the desk, was also something we 
CHANGING THE REFERENCE SERVICE MODEL

wished to emphasize in the new desk model. Our previous desk was extremely traditional. A standing height, wood giant. While aesthetically pleasing, it did not invite students to visit and spend any considerable time. Students had to remain standing during any interactions, and often lean across the desk to view anything the librarian was trying to demonstrate. With the traditional setup, it was almost impossible to turn the computer monitor to an easily viewable position (and occasionally when trying, cords would loosen and the monitor would turn black). In addition to being inconvenient and imposing, the desk was not accessible at all. To remedy both of these issues, the BearClaw drop-in tutoring model provides a perfect example of the direction we wanted to go.

Once we had identified two major avenues of change (desk and service), we started looking at ways to make that happen. As noted above, during this time we also changed the name of our department from Reference and Government Information to the Research and Instructional Services Unit. This name better indicates the mission and vision of our unit, and the ways our focus as a unit has shifted. Hashing out the details of our service model was our first step. From the onset of our discussions, we had shifted evening and weekend desk hours, those traditionally held by a librarian, to student workers. Our statistics indicated we would not miss an overwhelming number of reference questions by doing so. Prior to changing desk hours and staffing, we noted that between the weeknight hours of 10:00 p.m. and midnight that we had an average of one reference question per hour. Sundays and weeknight hours between 6:00 and 10:00 indicated limited reference interactions also. We continued to monitor reference questions asked at the new desk model between 6:00 and 10:00pm, and averaged only 2.8 reference questions per week during that time frame. Select hours are covered by a faculty librarian, but many are covered by library staff and student workers, with a faculty librarian as backup. During their desk backup time a librarian can work in their office, take research consultations, prep for classes (and in some instances still teach classes). This leaves considerably more time for committee work, preparation for classes and research consultations, and pursuing our own research agenda. Our student worker training was also 
CHANGING THE REFERENCE SERVICE MODEL

modeled off the BearClaw Tutoring and Writing Center. Student workers received intensive training up front (completion of library tutorials, active learning workshops, role playing, etc.). They were then paired with an experienced student worker, whom they shadowed. Faculty librarians also assisted with the shadowing when possible. This comprehensive and iterative training empowered student workers to be more than a stop gap at the desk. They provided 'tutoring' in reference and information literacy skills. The student workers' investment in this service model has been one of the most rewarding aspects of this endeavor.

During the time we were able to fully implement our preferred model, the physical desk itself was much changed. It was a U-shaped configuration of desks, with library workers seated on the inner part of the ' $U$ ', and those seeking research help were seated around the outside. These were working height tables; students could easily sit down and be comfortable for the duration of their interaction. There were two computer stations, with the computer monitors on swiveling bases. This allowed both the library worker and person seeking help to easily view the computer and watch the research process. If needed, we could also pass the student the keyboard and involve them in the search process. The new arrangement was also accessible. We could easily accommodate those in wheelchairs, plus, the ability to sit during the interaction helped those who couldn't stand comfortably for extended periods. We worked with our oncampus Planning Design and Construction office to facilitate the new desk setup. It took some adjusting to make our vision a reality, one obstacle in making our vision a reality was the power availability in the desk space. We had hoped to move forward with tabletop power, so we would not be tethered to floor outlets. This would have allowed us to move the desk forward, and angle it, for maximum visibility as students enter the first floor of the library. One goal of moving to this style of desk was to have flexibility in arranging our space as the needs of our campus community shift and change.

\section{Student Employees.}

In addition to changing our service model and space, student employee hiring and training was also revamped. For hiring student employees for the new desk model, we reviewed our job position postings 
CHANGING THE REFERENCE SERVICE MODEL

and our interview questions. We added more details to the responsibilities of the position description and we also added more behavior-based questions to ask during the interview process (see appendix A).

We established a checklist of training items to cover with each student worker. These included basics such as general protocols, desk procedures, tours of the building and the website, and introductions to faculty librarians. The checklist also included more in-depth items students had to be trained on including the reference interview, chat and phone etiquette, searching for information using library resources, and knowing when to contact your faculty librarian backup. This checklist was used for any new hires and was intended to be covered in segments throughout their first two weeks. During this time, a faculty librarian or a highly trained student worker would be at the desk with the new student. A worksheet with training exercises was given to each student at the end of the training to ensure they could handle basic reference questions on their own. The worksheet covered basic searches in the catalog and select general databases such as JSTOR, Lexis Nexis (now Nexis Uni), and Academic Search Complete. Other questions from the worksheet ensured students could find a subject-specific database, peer-reviewed article, and specific journals. At the beginning of every semester, all RIS student employees had a mandatory in-person two-hour training covering customer service, the reference interview, common research assignments, overview of desk procedures, and updates or changes from previous semesters (see appendix B for training PowerPoint). This was also a time for RIS students to get to know each other and the Head of RIS. Customer service was always an important aspect of the training and of the student employee position, but the importance of customer service was emphasized with the new service model. Training focused not just on helping patrons and sending them away, but on spending time with each to ensure they felt they actually knew the information they needed before leaving. It was more of a teaching experience for our student employees versus a simple demonstration as it had been at the previous reference desk.

We did receive feedback from our student workers on the work they were able to perform. Because of the amount and type of training they had received and the new desk configuration, our student workers were 
CHANGING THE REFERENCE SERVICE MODEL

able to have lengthy reference interactions with patrons. Patrons now had the ability to sit and work with our students for longer periods of time which sometimes prevented them from needing to come back at a different time to work with a librarian. Our student workers also had the capacity to work with groups of patrons. For example, we received reports that several high school students needed research assistance on the same assignment. The high school students were able to sit around the new research help desk while three student workers assisted them. We had several reports of research interactions lasting longer than 15 minutes.

Another example reported from our student workers was a student whose first language was not English. This specific student had a research assignment from a psychology class that she was struggling to complete. Two of our student workers helped the student not only learn how to navigate our databases but provided her with an extra support component. Our student workers assisted her for an hour to make sure she did not leave still feeling confused. We believe that the ability to help patrons (mostly our campus student population) in this way is invaluable. Our patrons were more likely to receive the research assistance they needed at the actual point of need while also not feeling rushed. The desk configuration paired with our new model allowed for us to expand past the previous "show and tell" style of larger reference desks.

\section{Discussion}

We were able to maintain our ideal space and service model for a little over a year, and our anecdotal evidence confirmed it was exactly the right move for us. We were a destination; this style of service point created the space we wanted, and students needed. We were able to spend more quality time on teaching research, while maximizing the time of our faculty librarians. The learner-centered approach let students walk away not only with the materials they needed that moment, but skills useful for a lifetime. Due to budget constraints and changing operational structure in Meyer Library, the Reference Desk, Circulation, and Music and Media service points were combined and are staffed by student workers with library staff backup. It is unfortunate we had our ideal for such a short time, as robust assessment was not managed. We did keep statistics of types and numbers of questions. We collected these by using 
CHANGING THE REFERENCE SERVICE MODEL

a paper chart at the desk and used tally marks to indicate type. We were able to compare the number of reference questions for each Fall semester (generally, our busiest semester). The final fall semester for our traditional reference desk (Fall 2015) we had 2,627 reference questions. Summer of 2016 we moved to a temporary service point location for our new desk model, but it was not fully implemented until Fall 2017. We had the following number of reference questions: Fall 2016, 2,094; Fall 2017, 2,254; Fall 2018, 2,126; It's worth noting during the spring and summer 2018 there was major work done to the terrazzo near and around our service area which we believe skewed our numbers.

The combined desk model (previously mentioned) began on July 1, 2019. Gathering desk statistics continued, but changed from tally marks on a paper chart to using RefAnalytics in October 2019. For Fall 2019, we show 369 reference questions for the newly combined desk. With all the changes resulting from combining desks and how we collect statistics, we believe the statistics gathered may not be fully representative of all reference interactions that occurred. However, it's important to note that a 1,757 drop in the number of questions is significant. It is also important to note that during this transition time to a new combined desk, we had to hire many new student employees, the training model changed, and additional library staff were given supervisory duties while RIS transitioned away from overseeing a service point.

For those libraries interested in moving toward a more unique space and service model, we recommend securing assurance with financial considerations, staffing, and support. For our own assessment, we would have liked to collect data such as: assessing internal and external perceptions of the desk, the types of questions received, how they are being answered, and what additional ways can we use the space to optimize our service model (specialty drop-in nights for Veteran or First-Generation students for example). We did identify things we would change, the first, we would have created a custom desk configuration. The tables we had functioned but lacked aesthetic cohesion. Signage was another thing needing improvement in our model. We had a tabletop sign, but this was not readable from our main entry point and lacked a directional component. We were eventually able to utilize wrap signage on a 
CHANGING THE REFERENCE SERVICE MODEL

column behind our space to indicate more clearly what we were, and direct students as they entered the main part of the library.

As mentioned above, the engagement and investment of our student workers was one of the best aspects of this service. Prior to the desk combinations, the students were working together to design student worker shirts and vests. We loved getting to work closely with them, get their feedback, make connections, and in the long run, develop strong library alumni.

The benefit from even the limited time we implemented this model was transformative to our faculty time. Our institution is not alone with faculty being stretched thin. This model allows faculty librarians to continue as experts in reference efforts (taking some desk time and having challenging reference queries referred from student workers) but optimizes most of our day. Library faculty involvement in areas of teaching, service, and research is crucial to the advancement of our profession. Not being tied to a desk allows flexibility and growth in these vital areas. 
CHANGING THE REFERENCE SERVICE MODEL

\section{References}

Alexander, S. \& Wakimoto, D. K. (2019). Exploration of reference models in a public university system. Reference Services Review, 47(1), 21-36. https://doi.org/10.1108/RSR-08-20180062

McClure Hazel, \& Bravender Patricia. (2013). Regarding Reference in an Academic Library: Does the Desk Make a Difference? Reference and User Services Quarterly, 52(4), 302308.

Nims, J.K., Storm, P., \& Stevens, R. (2014). Implementing an inclusive staffing model for

today's reference services: A practical guide for librarians. Rowan \& Littlefield.

O’Kelly, M., Garrison, J., Merry, B., \& Torreano, J. (2015). Building a Peer-Learning Service for Students in an Academic Library. Portal: Libraries and the Academy, 15(1), 163 182. http://dx.doi.org/10.1353/pla.2015.0000 